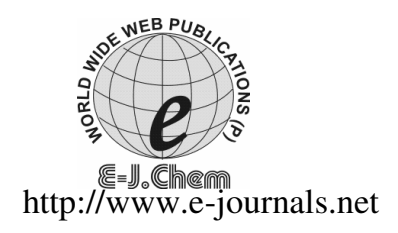

ISSN: 0973-4945; CODEN ECJHAO

E-Journal of Chemistry $2011, \mathbf{8}(2), 910-916$

\title{
One-Pot Synthesis of 1,8-Dioxo-octahydroxanthenes Utilizing Silica-Supported Preyssler Nano Particles as Novel and Efficient Reusable Heterogeneous Acidic Catalyst
}

\author{
ALI JAVID ${ }^{\S *}$, MAJID M. HERAVI and FATEMEH F. BAMOHARRAM ${ }^{\S}$ \\ ${ }^{\S}$ Department of Chemistry, School of Sciences \\ Islamic Azad University, Mashhad Branch, Mashhad, Iran \\ Department of Chemistry \\ Azzahra University, Vanak, Tehran, Iran \\ alijavids@yahoo.com
}

Received 9 June 2010; Accepted 31 August 2010

\begin{abstract}
A highly efficient one-pot synthesis of 1,8-dioxo-octahydroxanthenes from dimedone and various aromatic aldehydes under reflux conditions in water, catalyzed by silica-supported preyssler nano particles (SPNP) is reported. The products were formed in excellent yields and the acidic catalyst was completely heterogeneous and can be recycled for many times.
\end{abstract}

Keywords: One-pot synthesis, 1,8-Dioxo-octahydroxanthene, Heteropoly acids, Nanocatalyst.

\section{Introduction}

Xanthene and their derivatives are an important family of organic compounds because they have wide range of biological and pharmaceutical properties such as antibacterial ${ }^{1}$, antiviral $^{2}$, anti-inflammatory ${ }^{3}$, anti-depressants and antimalarial agents ${ }^{4}$. Also, they are as structural unit in a number of natural products ${ }^{5}$ and santalin pigments isolated from a number of plant species are major sources for xanthenes ${ }^{6}$. Furthermore, these compounds are utilized in industries as leuco-dye $\mathrm{e}^{7}$, in laser technology $\mathrm{y}^{8}$, as $\mathrm{pH}$ sensitive fluorescent materials for the visualization of biomolecular assemblies ${ }^{9}$ and used in photodynamic therapy ${ }^{10}$. Recently, xanthenes have been used as rigid carbon skeletons for the construction of new chiral bidentate phosphine ligands with potential applications in catalytic processes ${ }^{11}$.

Even though, various methods have been reported for preparation of xanthenes and substituted xanthenes. The classical method for the synthesis of 1,8-dioxo-octahydro xanthenes involves the condensation of appropriate active methylene carbonyl compounds with aldehydes ${ }^{12}$. For this purpose, react two molecules of dimedone (5,5-dimethyl-1,3cyclohexane dione) with various aromatic aldehydes ${ }^{13}$, by using of different Lewis acid catalysts such as triethylbenzyl ammonium chloride ${ }^{14}, p$-dodecyl benzenesulfonic acid $^{15}$, diammonium 
hydrogen phosphate under various conditions ${ }^{16}$, sulfonic acid under ultrasonic irradiation ${ }^{17}$, ionic liquids ${ }^{18}$, Amberlyst- $15^{19}, \mathrm{NaHSO}_{4}-\mathrm{SiO}_{2}$ or silica chloride ${ }^{20}$, phosphomolybdic acid supported on silica gel ${ }^{21}$, nanosized MCM-41- $\mathrm{SO}_{3} \mathrm{H}$ under ultrasonic irradiation ${ }^{22}$, sulfonic acid on silica gel ${ }^{23}$, Dowex-50W ion exchange resin under solvent-free conditions ${ }^{24}, \mathrm{HClO}_{4}-\mathrm{SiO}_{2}{ }^{25}, \mathrm{ZnO}$ and $\mathrm{ZnO}$ acetyl chloride ${ }^{26}$ and heteropoly acid supported MCM- $41^{27}$.

It is worth noting that most of these techniques have problems such as long reaction times, low efficiency, expensive raw materials, toxic materials and catalysts, hazard organic solvents, tedious workup, use of excess of reagents/catalysts and side reactions of aldehydes. Therefore, to avoid these limitations, the usage of a new and efficient catalyst with high catalytic activity, short reaction time, recyclable, suitable for green chemistry and easy to work-up for preparation of 1,8-dioxo-octahydroxanthenes would be highly desirable.

In the last two decades, heteropoly acids (HPAs) have found numerous applications as useful and versatile acid catalysts for some acid-catalyzed reactions. Heteropoly acids are several times more active than inorganic and organic acids and their molar catalytic activity is 100-1000 times more active than $\mathrm{H}_{2} \mathrm{SO}_{4}$. They can also be used in low concentrations ${ }^{28}$. HPAs are nontoxic, highly stable towards humidity, air stable, recyclable, compatible with the environment, ease of handling and experimental simplicity ${ }^{29}$. So, in recent years, heteropoly acids were used in different reactions and synthesizes as Lewis acid catalyst ${ }^{30}$. Of course, the need for character development and optimization of catalytic efficiency of heteropoly acids to be felt.

Recently, because of the unique properties of nano particles, synthetic chemists focused on nano-catalysts. Therefore, synthesis and characterization of catalysts with lower dimensions have become the most interesting topic of research. We know that as the particle size decreases, the relative number of surface atoms increases and thus the activity increases ${ }^{31}$. Moreover, due to quantum size effects, nanometer-sized particles may exhibit unique properties for a wide range of applications ${ }^{32}$.

We have reported in our earlier paper $^{33}$ about the synthesis and characterization of silica-supported Preyssler nano catalyst. A Preyssler acid is a highly acidic catalyst from heteropoly acid family with excellent catalytic activity in a variety of acid-catalyzed reactions ${ }^{30}$. Therefore, we hope that to get better the behaviors of this catalyst with nano particle size in organic reactions and synthesizes.

\section{Experimental}

Silica-supported Preyssler nano particles catalyst was synthesized according to our previous report $^{33}$. For synthesis of this catalyst, to a solution of surfactant in cyclohexan $(0.2 \mathrm{M})$, a solution of Preyssler acid in a specified amount of water was added. The molar ratio of water to surfactant selected was 3, 5 and 7 . Then, tetraethoxysilan was added into the micro emulsion phase. After mixing for various times $(8,12,18,25$ and $30 \mathrm{~h})$ at room temperature, dispersed Preyssler acid $/ \mathrm{SiO}_{2}$ nano structures were centrifuged $(1500 \mathrm{rpm})$ and the particles were rinsed with acetone (4 times) and dried in a vacuum oven. The optimum ratio of water to surfactant was 3:1 and the optimum time was $30 \mathrm{~h}$.

\section{Preparation of 1,8-dioxo-octahydroxanthenes}

The work-up procedure of this reaction is very easy. To a solution of aromatic aldehyde $(2 \mathrm{mmol})$ and dimedone $(2 \mathrm{mmol})$ in water $(10 \mathrm{~mL})$ was added silica-supported Preyssler nanoparticles catalyst $(0.05 \mathrm{mmol})$. The mixture was refluxed for $3 \mathrm{~h}$. After completion of the reaction (the progress of the reaction was monitored by TLC using $n$-hexan: ethylacetate as eluent), the mixture was cooled and the solid residue was separated and dissolved in dichloromethane. The solution was filtered and solid SPNP catalyst was isolated and could 
be reused. The organic phase was evaporated and the reaction mixture was recrystallized in ethanol to give pure product. All the products are known compounds and the spectral properties and melting points of them matched well with those reported earlier ${ }^{23,25}$. Spectroscopic and physical data of some representative compounds are given below.

\section{3,3,6,6-Tetramethyl-9-phenyl-1,8-dioxooctahydroxanthene (2a)}

${ }^{1} \mathbf{H}$ NMR(100 MHz, DMSO-d $\left.{ }_{6}\right) \delta(\mathrm{ppm}): \delta 0.86\left(\mathrm{~s}, 6 \mathrm{H}, 2 \mathrm{CH}_{3}\right), 1.00\left(\mathrm{~s}, 6 \mathrm{H}, 2 \mathrm{CH}_{3}\right), 2.11-2.25$ $\left(\mathrm{d}, 4 \mathrm{H}, 2 \mathrm{CH}_{2}\right), 2.42\left(\mathrm{~s}, 4 \mathrm{H}, 2 \mathrm{CH}_{2}\right), 4.53(\mathrm{~s}, 1 \mathrm{H}, \mathrm{CH}), 7.14(\mathrm{~m}, 5 \mathrm{H}, \mathrm{Ph}) ; \mathbf{I R}\left(\mathrm{KBr}, \mathrm{cm}^{-1}\right) v_{\max }$ : 2959, 1662, 1624, 1360, 1197, 1166, 1139, 1001; MS(m/z): 350( $\left.\mathrm{M}^{+}\right), 273,217,77$.

\section{3,3,6,6-Tetramethyl-9-(4-chlorophenyl)-1,8-dioxooctahydroxanthene(2c)}

${ }^{1} \mathbf{H}$ NMR(100 MHz, DMSO-d $\left.{ }_{6}\right) \delta(\mathrm{ppm}): \delta 0.86\left(\mathrm{~s}, 6 \mathrm{H}, 2 \mathrm{CH}_{3}\right), 1.00\left(\mathrm{~s}, 6 \mathrm{H}, 2 \mathrm{CH}_{3}\right), 2.12-2.22$ $\left(\mathrm{d}, 4 \mathrm{H}, 2 \mathrm{CH}_{2}\right), 2.39\left(\mathrm{~s}, 4 \mathrm{H}, 2 \mathrm{CH}_{2}\right), 4.48(\mathrm{~s}, 1 \mathrm{H}, \mathrm{CH}), 7.1-7.2(\mathrm{dd}, 4 \mathrm{H}, \mathrm{Ph}) ; \mathbf{I R}\left(\mathrm{KBr}, \mathrm{cm}^{-1}\right) \mathrm{v}_{\max }$ :

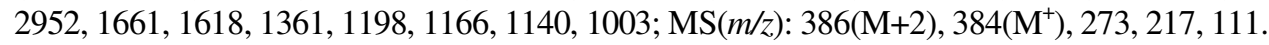

\section{Results and Discussion}

In this study and in continue of our work with heteropoly acids as catalyst in organic reactions ${ }^{30}$, we synthesized 1,8-dioxo-octahydroxanthenes derivatives (2a-g) via a one-pot reaction of aromatic aldehyde (1) and dimedone in presence of silica-supported Preyssler nano particles (SPNP) catalyst and reflux conditions in water as solvent in excellent yields in this work (Scheme 1).

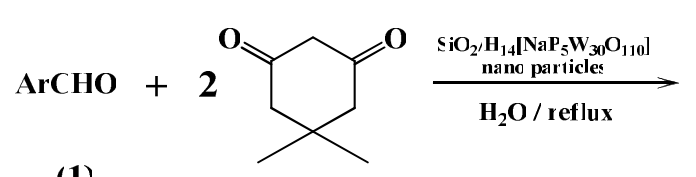

(1)<smiles>CC1(C)CC(=O)C2=C(C1)OC1=C(C(=O)CC(C)(C)C1)C2[Al]</smiles>

(2a-g)

Scheme 1. One-pot reaction for the preparation of 1,8-dioxo-octahydroxanthenes derivatives (2a-g) in water
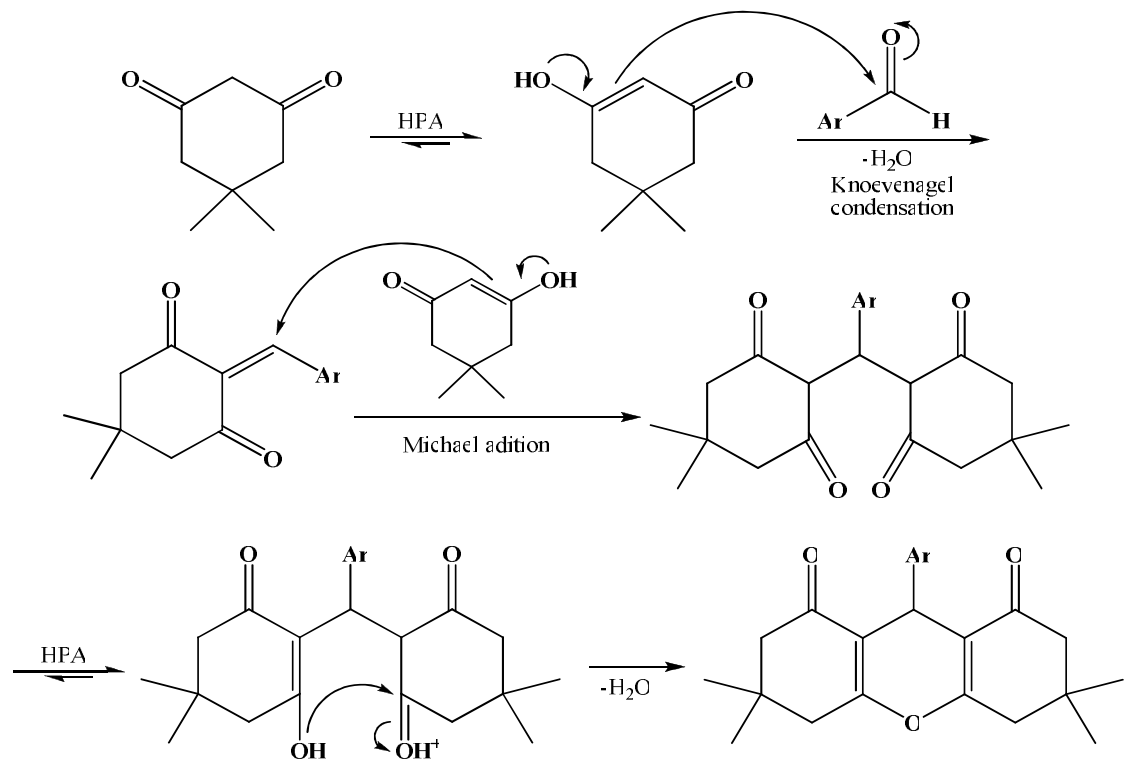

Scheme 2. Proposed mechanism for HPA catalyzed 1,8-dioxo-octahydroxanthenes synthesis 
The mechanism of the reaction was proposed in Scheme 2. As can be seen, reaction proceeds via one-pot Knoevenagel condensation, Michael addition and cyclodehydration. We think that acid catalyst such as heteropoly acids might promote the reaction by accelerating the formation of enol from the 1,3-dicarbonyls such as dimedone, in the ratedetermining step (Scheme 2).

To find simple and suitable conditions for synthesis of 1,8-dioxo-octahydro xanthenes derivatives, the reaction of benzaldehyde 1a and dimedone was chosen as a model to form the 3,3,6,6-tetramethyl-9-phenyl-3,4,5,6,7,9-hexahydro-1H-xanthene-1,8(2H)-dione $2 \mathbf{a}$ and reaction progress was studied under different conditions by Thin Layer Chromatography (TLC).

A summary of obtained results have been shown in Table 1. As is observable, the reaction is not performed in the absence of catalyst (Table 1, entry 1). Also, the reaction was done when Preyssler heteropoly acid used as catalyst (Table 1, entry 2-5) and it should be mentioned that use of $0.5 \mathrm{~mol} \% \mathrm{H}_{14}\left[\mathrm{NaP}_{5} \mathrm{~W}_{30} \mathrm{O}_{110}\right]$ is sufficient to push the reaction forward and larger amounts of the catalyst did not improve the results to a greater extent. Of course, silica-supported Preyssler nano particles (SPNP) acid catalyst, showed higher catalytic activity than Preyssler alone. Then, the best ratio of aromatic aldehyde, dimedone and SPNP catalyst at mole is 1:2: 0.05. It is noteworthy that the reactions were completed after about three hours and more time, did not influence on the reaction process.

Table 1. Effect of various Preyssler acid catalyst amount on xanthene synthesis

\begin{tabular}{ccc}
\hline Entry & Amount of catalyst, mol $\%^{\mathrm{a}}$ & Yield, $\%^{\mathrm{b}}$ \\
\hline 1 & 0 & trace \\
2 & 0.1 , Preyssler & 47 \\
3 & 0.3 , Preyssler & 66 \\
4 & 0.5, Preyssler & 82 \\
5 & 0.6, Preyssler & 83 \\
6 & 0.3, SPNP & 79 \\
7 & 0.4, SPNP & 86 \\
8 & 0.5, SPNP & 93 \\
\hline
\end{tabular}

a) Reaction of benzaldehyde 1 a $(1 \mathrm{mmol})$ and dimedone $(2 \mathrm{mmol})$ in presence of different amount of Preyssler and silica-supported Preyssler nano particles (SPNP) acid catalyst under reflux conditions in water. b) Isolated yield after $3 \mathrm{~h}$ reflux

Also, the effect of various solvents on the rate of the reaction was studied (Table 2). As can be seen, ethanol and water were favorable solvents for this synthesis. But water was chosen, because it is acceptable solvent for green chemistry and environment.

Table 2. Effect of various solvents on xanthene synthesis

\begin{tabular}{ccc}
\hline Entry & Solvent & Yield of xanthenedione, $\%^{\text {a }}$ \\
\hline 1 & Ethanol & 95 \\
2 & Methanol & 68 \\
3 & Acetonitrile & 57 \\
4 & Ethyl acetate & 71 \\
5 & Water & 93
\end{tabular}

a) Reaction of benzaldehyde 1 a $(1 \mathrm{mmol})$ and dimedone $(2 \mathrm{mmol})$ in presence of SPNP acid catalyst $(0.5$ mol \%) after 3 h reflux 
The results of optimized reaction can be seen in Table 3. As is observable, by using this nanocatalyst, the aromatic aldehydes containing both electron-donating and electronwithdrawing groups afforded the products with excellent yields; although, electronwithdrawing groups were slightly better.

Table 3. One-pot synthesis of 1,8-dioxo-octahydroxanthenes using catalytic amount of SPNP as catalyst

\begin{tabular}{ccccc}
\hline Entry & Aldehyde & Product & Yield, $\%^{\text {a }}$ & M.P, ${ }^{\circ} \mathrm{C}$ \\
\hline 1 & $\mathrm{C}_{6} \mathrm{H}_{5} \mathrm{CHO}$ & $\mathbf{2 a}$ & 93 & $203-205$ \\
2 & $4-\mathrm{CH}_{3} \mathrm{C}_{6} \mathrm{H}_{4} \mathrm{CHO}$ & $\mathbf{2 b}$ & 89 & $219-221$ \\
3 & $4-\mathrm{ClC}_{6} \mathrm{H}_{4} \mathrm{CHO}$ & $\mathbf{2 c}$ & 95 & $231-233$ \\
4 & $3-\mathrm{ClC}_{6} \mathrm{H}_{4} \mathrm{CHO}$ & $\mathbf{2 d}$ & 90 & $192-194$ \\
5 & $4-\mathrm{CH}_{3} \mathrm{OC}_{6} \mathrm{H}_{4} \mathrm{CHO}$ & $\mathbf{2 e}$ & 82 & $248-250$ \\
6 & $4-\mathrm{NO}_{2} \mathrm{C}_{6} \mathrm{H}_{4} \mathrm{CHO}$ & $\mathbf{2 f}$ & 96 & $228-230$ \\
7 & $4-\mathrm{BrC}_{6} \mathrm{H}_{4} \mathrm{CHO}$ & $\mathbf{2 g}$ & 92 & $231-233$ \\
\hline \multicolumn{5}{c}{ Isolated yield after 3 h reaction }
\end{tabular}

This nano catalyst also showed excellent reusability in these reactions (Table 4).

Table 4. Recyclability of supported nano catalysts

\begin{tabular}{cc}
\hline Cycles & Isolated yield of xanthenedione, $\%^{\mathrm{a}}$ \\
\hline Fresh & 93 \\
1 & 89 \\
2 & 85 \\
3 & 81 \\
\hline uld be recycled by washing with diethyl ether and dried at $100^{\circ} \mathrm{C}$ for $3 \mathrm{~h}$
\end{tabular}

\section{Conclusion}

Silica-supported Preyssler nano particles (SPNP) is a highly efficient, reusable and green solid acid catalyst for the synthesis of 1,8-dioxo-octahydroxanthenes via a one-pot condensation reaction of aromatic aldehydes and dimedone in water as green solvent and reflux conditions. Excellent yields, enhanced reaction rates and short reaction times, simplicity of operation and easy work-up are some advantages of this protocol. Also, Preyssler is a cheap, stable, reusable and agreeable with environment catalyst. Hence, we believe that this method will find wide application in organic synthesis as well as industry.

\section{References}

1. Hideo T, Tokkyo Koho JP 56005480, 1981, Chem Abstr., 1981, 95, 80922b, Jpn.

2. Lambert R W, Martin J A, Merrett J H, Parkes K E B and Thomas G J, PCT Int Appl.,WO9706178, 1997, Chem Abstr., 1997, 126, p212377y.

3. Poupelin J P, Saint-Rut G, Fussard-Blanpin O, Narcisse G, Uchida-Ernouf G and Lakroix R, Eur J Med Chem., 1978, 13, 67-71.

4. Chibale K, Visser M, Schalkwyk D V, Smith P J, Saravanamuthu A and Fairlamb A H, Tetrahedron, 2003, 59, 2289-2296.

5. (a) Hatakeyma S, Ochi N, Numata H, and Takano S, J Chem Soc Chem Commun., 1988, 1202-1204; (b) Cingolant G M and Pigini M, J Med Chem., 1988, 12, 531. 
6. (a) Arnone A, Merlini L and Nasini G, Tetrahedron Lett., 1972, 3503; (b) Ravindranath B and Sheshadri T R, Phytochemistry 1973, 12, 2781; (c) Kinjo J, Uemura H, Nohara T, Yamashita M, Marubayashi N and Yoshihira K, Tetrahedron Lett., 1995, 36, 5599-5602.

7. Banerjee A and Mukherjee A K, Stain Technol., 1981, 56, 83-85.

8. (a) Menchen S M, Benson S C, Lam J Y L, Zhen W, Sun D, Rosenblum B B, Khan S H and Taing M, U.S. Patent, US6583168, 2003, Chem Abstr., 2003, 139, p54287f;

(b) Sirkecioglu O, Tulinli N and Akar A, J Chem Res (S), 1995, 502-506.

9. (a) Bekaert A, Andrieux J and Plat M, Tetrahedron Lett. 1992, 33, 2805; (b) Sarma R J and Baruah J B, Dyes Pigm., 2005, 64, 91-92; (c) Buehler C A, Cooper D E and Scrudder E O, J Org Chem., 1943, 8, 316; (d) Knight C G and Stephens T, Biochem J., 1989, 258, 683-687.

10. (a) Ion R M, Frackowiak D, Planner A, and Wiktorowicz K, Acta Biochim Pol., 1998, 45, 833-845; (b) Ion R M, Prog Catal., 1997, 6, 55.

11. (a) Hamada Y, Matsuura F, Oku M, Hatano K and Shioiri T, Tetrahedron Lett., 1997, 38, 8961-8964; (b) Hillebrand S, Bruckmann J, Kruger C and Haenel M W, Tetrahedron Lett., 1995, 36, 75-78; (c) Malaise G, Barloy L and Osborn J A, Tetrahedron Lett., 2001, 42, 7417-7419.

12. Kuthan J, Sebek P and Bohm S, Advances in Heterocyclic Chemistry; Academic Press lnc: New York, 1995,62, 19.

13. (a) Horning E C and Horning M G, J Org Chem., 1946, 11, 95-99; (b) Tu S J, Zhou J F, Lu Z S, Deng X, Shi D Q and Wang S H, Synth Commun., 2002, 32, 3063-3067; (c) Jin, T S, Zhang J S, Wang A Q and Li T S, Synth Commun., 2005, 35, 2339.

14. Wang X S, Shi D Q, Li Y L, Chen H, Wei X Y and Zong Z M, Synth Commun., 2005, 35, 97.

15. Jin T S, Zhang J S, Xiao J C, Wang A Q and Li T S, Synlett., 2004, 866.

16. Darvish F, Balalaei S, Chadegani F and Salehi P, Synth Commun., 2007, 37, 1059-1067.

17. Jin T S, Zhang J S, Wang A Q and Li T S, Ultrason Sonochem., 2006, 13, 220.

18. Dabiri M, Baghbanzadeh M and Arzroomchilar E, Catal Commun., 2008, 9, 939-942.

19. Das B, Thirupathi P, Mahender I, Reddy V S and Rao Y K, J Mol Catal A Chem., 2006, 247, 233.

20. Das B, Thirupathi P, Mahender I, Reddy K R, Ravikanth B and Nagarapu L, Catal Commun., 2007, 8, 535.

21. Srihari P, Mandal S S, Reddy J S S, Srinivasa Rao R and Yadav J S, Chin Chem Lett., 2008, 19, 771.

22. Rostamizadeh S, Amani A M, Mahdavinia G H, Amiri G and Sepehrian H, Ultrason Sonochem., 2010, 17(12), 306-309.

23. Mahdavi G H, Bigdeli M A and Saeidi Hayeniaz Y, Chin Chem Lett., 2009, 20, 539.

24. Imani Shakibaei G, Mirzaei P and Bazgir A, Appl Catal A: General, 2007, 325, 188-192.

25. Kantevari S, Bantu R and Nagarapu L, J Mol Catal A: Chem., 2007, 269, 53-57.

26. Maghsoodlou M T, Habibi-Khorassani S M, Shahkarami Z, Maleki N and Rostamizadeh M, Chin Chem Lett., 2010, 21, 686-689.

27. Karthikeyan G and Pandurangan A, J Mol Catal A: Chem., 2009, 311, 36.

28. (a) Kozhevnikov I V, Chem Rev., 1998, 98, 171-198; (b) Mizuno N and Misono M, Chem Rev., 1998, 98, 199. 
29. Heravi M M and Sadjadi S, J Iran Chem Soc., 2009, 6, 1.

30. (a) Heravi M M, Sadjadi S, Mokhtari Haj N, Oskooie H A and Bamoharram F F, Catal Commun., 2009, 10(13), 1643-1646; (b) Heravi M M, Sadjadi S, Mokhtari Haj N, Oskooie H A, Hekmat Shoar R and Bamoharram F F, Tetrahedron Lett. 2009, 50, 943;

(c) Heravi M M, Sadjadi S, Sadjadi S, Oskooie H A and Bamoharram F F, Ultrasonics Sonochem., 2009, 16, 708; (d) Heravi M M, Sadjadi S, Sadjadi S, Oskooie H A and Bamoharram F F, Ultrasonics Sonochem., 2009, 16(6), 718-720; (e) Heravi M M, Sadjadi S, Oskooie H A, Hekmat Shoar R and Bamoharram F F, Tetrahedron Lett., 2009, 50, 662-666; (f) Heravi M M, Sadjadi S, Oskooie H A, Hekmat Shoar R and Bamoharram F F, Catal Commun., 2008, 9, 470; (g) Heravi M M, Sadjadi S, Oskooie H A, Hekmat Shoar R and Bamoharram F F, Catal Commun., 2008, 9, 504; (h) Hekmat Shoar R, Heravi M M, Sadjadi S, Oskooie H A and Bamoharram F F, Catal Commun., 2008, 9, 837-841; (i) Heravi M M, Bakhtiari K, Fatehi A and Bamoharram F F, Catal Commun., 2008, 9, 289-292; (j) Heravi M M, Alimadadi Jani B, Derikvand F, Bamoharram F F and Oskooie H A, Catal Commun., 2008, 10, 272.

31. (a) Alivisatos A P, Science, 1996, 271, 933; (b) Gilbert B, Huang F, Zhang H, Waychunas G A and Banfield J F, Science, 2004, 305, 651-654.

32. (a) Alivisatos A P, Science, 1996, 271, 933; (b) Zhang J and Dickson R M, J Phys Rev Lett., 2004, 93, 077402; (c) Michalet X, Pinaud F F, Bentolia L A, Tsay J M, Doose S, Li J J, Sundaresan G A, Wu M, Gambhir S S and Weiss S, Science, 2005, 307, 538.

33. Bamoharram F F, Heravi M M, Roushani M, Toosi M and Jodeyre L, Green Chem Lett Rev., 2009, 2(1), 35. 


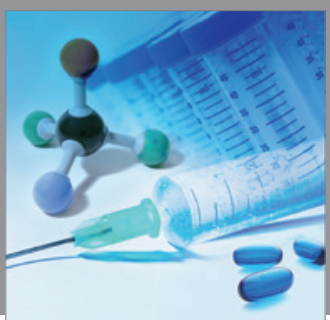

International Journal of

Medicinal Chemistry

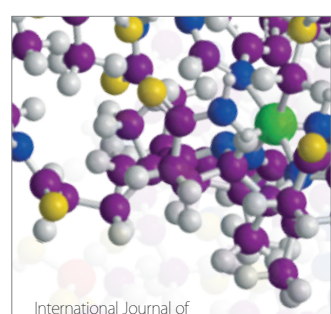

Carbohydrate Chemistry

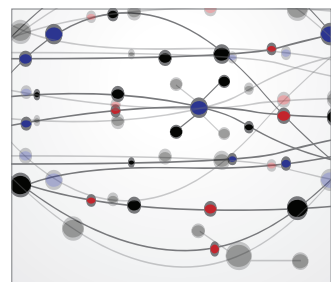

The Scientific World Journal
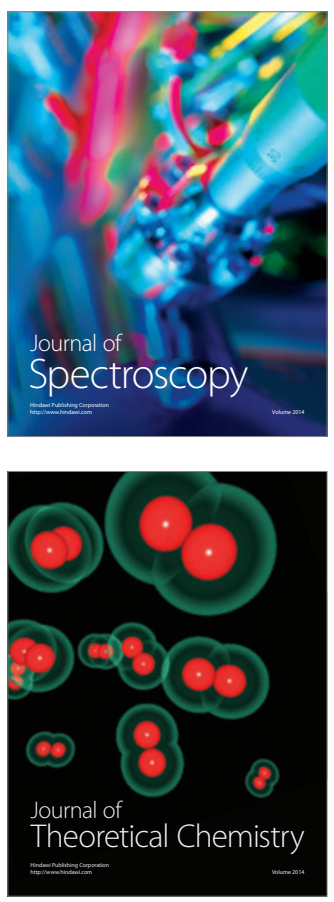
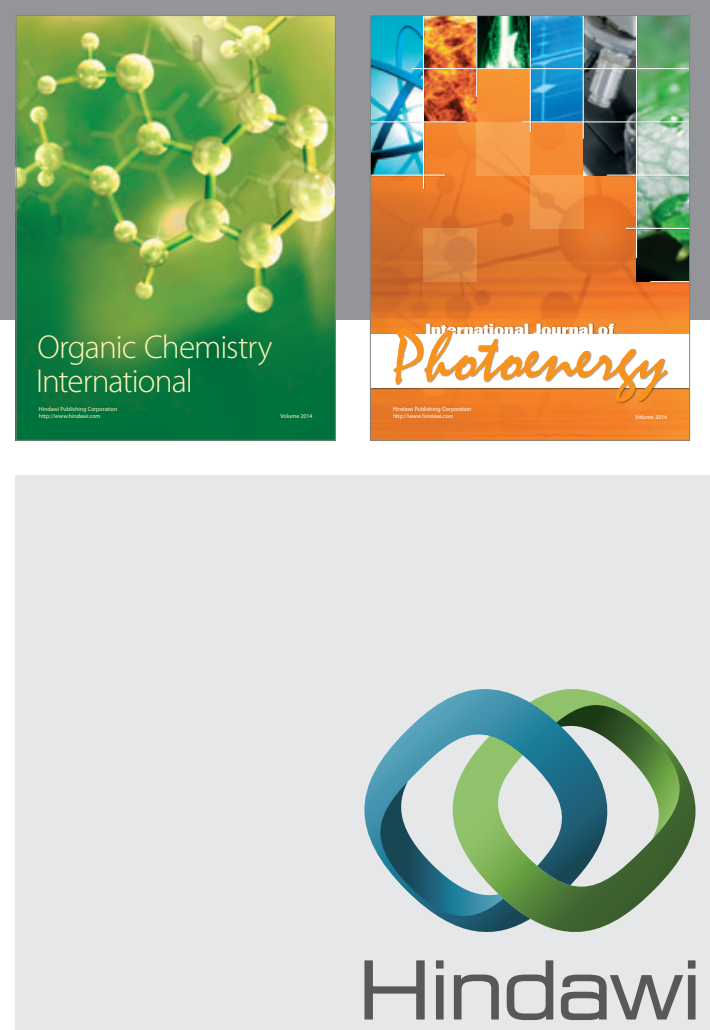

Submit your manuscripts at

http://www.hindawi.com
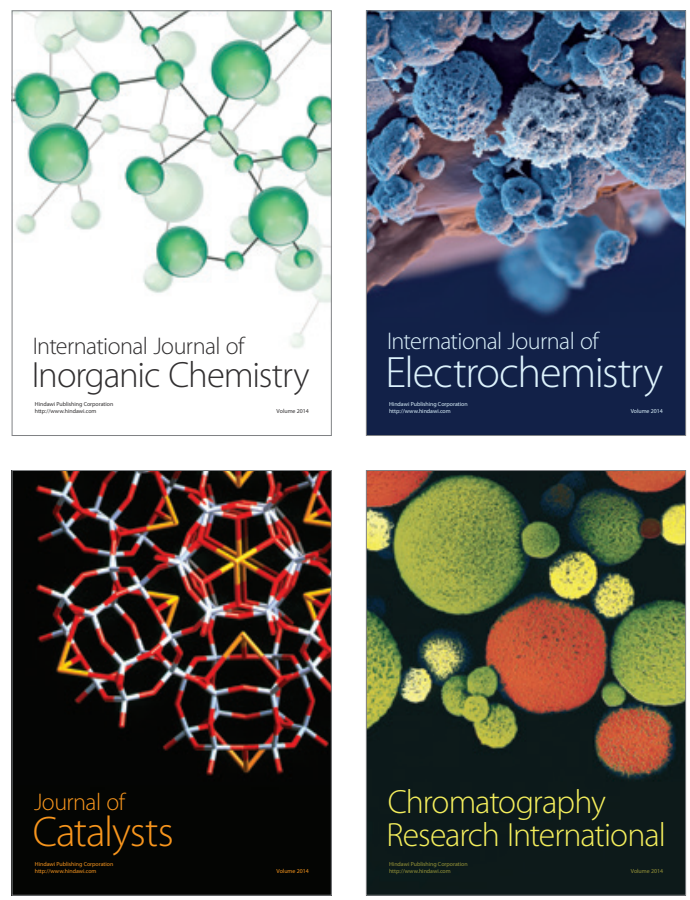
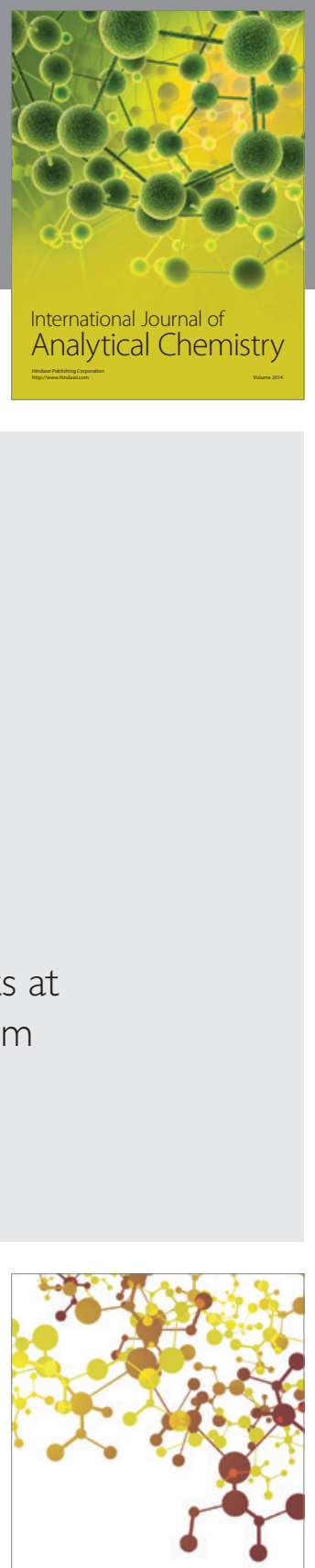

Journal of

Applied Chemistry
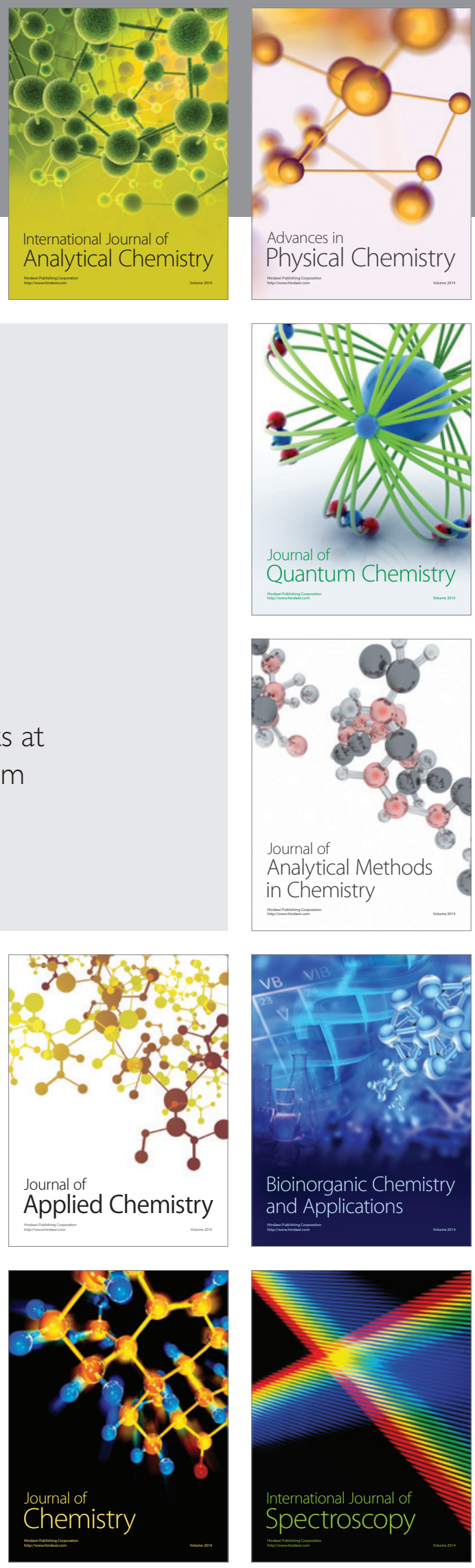